\title{
Analysis of Pesticide Residues in Rice Using Matrix Solid-Phase Dispersion (MSPD)
}

\author{
Haroldo S. Dórea* and Ledjane Lima Sobrinho
}

\author{
Departamento de Química, Universidade Federal de Sergipe, 49100-000 São Cristóvão-SE, Brazil
}

\begin{abstract}
Este trabalho apresenta um método multirresíduo de extração por dispersão da matriz em fase sólida (MSPD) para quantificação de dois inseticidas organofosforados (malation e paration metílico) e um organoclorado ( $\beta$-endosulfan) em arroz por cromatografia gasosa de alta resolução com detector por captura de elétrons. Experimentos foram realizados com adição de pesticidas na amostra, variando quantidades de amostra e de suporte, tipo de suporte e solvente de eluição. A eficiência do método proposto foi demonstrada pelos valores médios de recuperação entre 75,5\% e 116,0\%, com valores de desvio padrão relativo entre $0,5 \%$ e $10,9 \%$, obtidos nas análises de recuperação com amostras fortificadas nos níveis de 0,5 a $10,0 \mathrm{mg} \mathrm{kg}^{-1}$. Os limites de detecção foram de 20 a 105 pg para os pesticidas estudados. Arroz comercial foi analisado para a aplicação do método.
\end{abstract}

This work reports a multi-residue extraction method based on matrix solid-phase dispersion (MSPD) and capillary gas chromatography - electron capture detection for quantification of two widely used organophosphorus insecticides (malathion and parathion-methyl) and an organochlorine pesticide ( $\beta$-endosulfan) in rice. A set of experiments was done with a spiked matrix with a standard mix, varying sample and solid phase amounts, solid phase and eluting solvent. Analyses of fortified rice samples were performed at different levels $\left(0.5-10.0 \mathrm{mg} \mathrm{kg}^{-1}\right)$. Mean recoveries from three replicates ranged from $75.5 \%$ to $116.0 \%$, with coefficients of variation from $0.5 \%$ to $10.9 \%$. The limit of detection was in the range of 20 to $105 \mathrm{pg}$ for the pesticides. Commercial rice was analyzed for method application.

Keywords: pesticide residues, rice, MSPD, GC/ECD analysis

\section{Introduction}

Rice is an important alimentary source throughout the world and the quality of the grain can be compromised by the presence of pesticide residues in this product. Brazil has a rice production of about 10 million tons. ${ }^{1}$

Pesticides are routinely used in integrated farm management programs to reduce possible losses due to pests. The presence of high levels of pesticides in the food supply may have human health implications and has increased the attention and need to control these organic pollutants. For this reason, monitoring programs have been implemented for determination of these chemicals in foods.

As is already known, determination of pesticides by chromatographic techniques (mainly GC analysis) requires an extensive and is time consuming step of sample preparation, prior to final determination. Several papers have focused mainly on improvements of this step that is a main source of errors and is very time consuming. The

* e-mail: haroldo@ufs.br miniaturization of this step (sample and solvent amount, extraction technique) is a way to decrease the time consumption. Thus, development of a new method for multiresidues analysis of pesticides in rice is important.

The extraction and quantitation of pesticide residues in a food matrix mostly involve liquid-liquid extraction with a great variety of solvents and adsorvents for cleanup $^{2-4}$ or the use of soxhlet extraction..$^{5}$ These methods usually require large volumes and various solvents, backwashing and re-extraction. Others extraction techniques, which usually are faster and consume smaller volumes of organic solvent, have been developed for some food samples, such as supercritical fluid extraction, ${ }^{6}$ solid-phase microextraction ${ }^{7}$ and solid-phase extraction. ${ }^{8}$ Multiresidue methods for pesticides analysis were discussed by Ahmed, ${ }^{9}$ who presented eight techniques for sample preparation.

Matrix solid-phase dispersion (MSPD) was introduced in $1989^{10}$ and involves blending a viscous, solid or semisolid sample with a solid phase. In Brazil, this new process was introduced in 1999 by Dórea and Lanças ${ }^{11}$ for analysis of pesticides in tropical fruits (cashew nut and passion fruit). 
Others works have utilized MSPD extraction for pesticide determination in fruits and vegetables, ${ }^{12,13}$ citrus fruits ${ }^{14}$ and other food samples. MSPD has recently been used for the determination of a new generation of fungicides in fruits and vegetables, ${ }^{15}$ however no work has been reported up to now for grains.

MSPD and SPE both use some of the principles applied in chromatography. However, MSPD is different from SPE. MSPD extraction has proven to be quite generic, with the same general approach proving to be applicable to the isolation of drugs, pesticides and other pollutants from animal tissues, fruits and vegetables. This method usually uses a relatively small sample blended in a mortar (or glass beaker) with a pestle, using a solid phase in a four-to-one ratio of solid phase to sample. ${ }^{16}$

The solid phase, such as silica, often has been derivatized to produce a bound organic phase, such as $\mathrm{C}_{8}$ or $\mathrm{C}_{18}$, on its surface. The solid serves as a shearing force during the blending with a mortar and pestle to disrupt the gross architecture of the sample, breaking the material into smaller pieces. Sample components disperse into the bound organic phase on the surface of the particle, leading to the complete disruption of the sample and to its dispersion over the surface. ${ }^{16}$

Once the MSPD blending process is complete, the material is transferred to a column constructed from a syringe barrel, or some other appropriate device, containing a frit or glass wool that retains the entire material. A second frit may be placed on top of the material and the sample with support compressed to form a column packing by using a modified syringe plunger. Elutions may be with the application of pressure on a vacuum box. ${ }^{16}$ Most MSPD elutions have been conducted by gravity flow and then it is not necessary to compress the support. ${ }^{11}$

Many MSPD procedures also use co-columns to obtain a further degree of fractionation and sample clean-up. The co-column material may be packed into the bottom of the same column as the MSPD material or attached as an external column. ${ }^{17}$

Choice of the eluting solvent for the column permits performing multiple or sequential elutions of the sample. The sample components can fractionate and this property has proven useful in isolating and identifying endogenous components. ${ }^{16,17}$

Several factors have been shown to effect performance in MSPD as the nature of the solid phase (silica versus polymers, pore size, endcapping); the nature of the bonded phase (normal-phase versus reverse-phase, total carbon content); pretreatment or modification of the sample $(\mathrm{pH}$ adjustment, etc.); the nature and sequence of elution solvent addition and, most specifically for MSPD, and the nature of the sample matrix. ${ }^{17}$ For the most part, these are the same factors that are known to influence the performance of most chromatographic procedures.

In this work, a matrix solid-phase dispersion extraction method was developed for separation and quantitation of the organophosphorus pesticides parathion-methyl and malathion, and the organochlorine pesticide $\beta$-endosulfan in rice samples by capillary gas chromatography - electron capture detection (GC-ECD). Two adsorvents were compared as solid phase and ethyl acetate was used as elution solvent. The univariate method has been used. Commercial rice samples from the Sergipe irrigation region
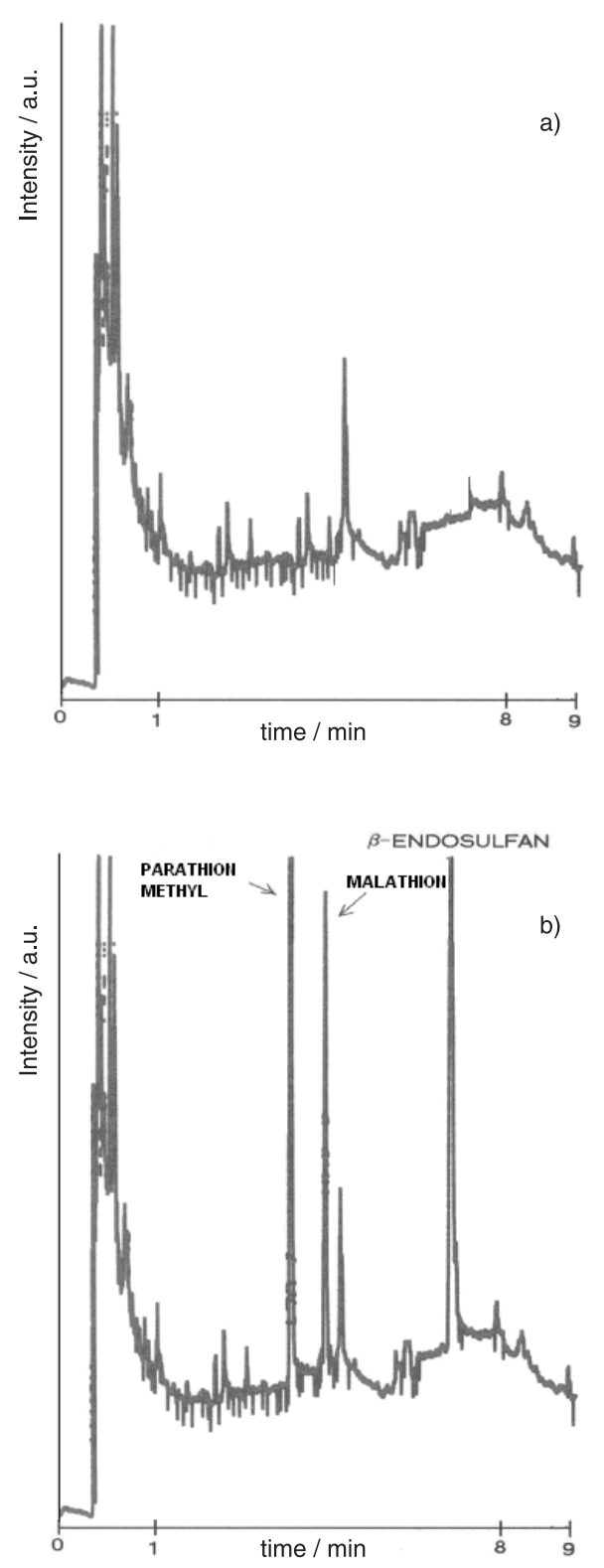

Figure 1. GC-ECD chromatograms: a) control rice sample and b) fortified rice sample spiked with parathion-methyl $(1.0 \mathrm{ng})$, malathion $(0.5 \mathrm{ng})$ and $\beta$-endosulfan $(2.0 \mathrm{ng})$. For conditions, see text. 
were analyzed for evaluation of the rice quality in the product that arrives for consumption.

\section{Experimental}

\section{Chemicals}

Ethyl acetate and hexane were from Merck. Adsorvents were: alumina (Sigma) and silica (Aldrich). Standards of the pesticides were: parathion-methyl (Annopol), malathion (Radian) and endosulfan (Promochem). All standard were at least $99.9 \%$ pure and the standard solutions were prepared each week in ethyl acetate and stored in freezer.

\section{Chromatographic analysis}

The Varian Star 3400 Cx gas chromatograph was equipped with an electron capture detector $\left({ }^{63} \mathrm{Ni}\right)$ and oncolumn injector. The detector and injector temperatures were $300{ }^{\circ} \mathrm{C}$ and $250{ }^{\circ} \mathrm{C}$, respectively. The column used was a DB-5 (5\% phenyl methylpolysiloxane stationary phase) $30 \mathrm{~m} \times 0.53 \mathrm{~mm}$ id fused silica capillary column coated with a $1.20 \mu \mathrm{m}$ film. The program temperature was: $180{ }^{\circ} \mathrm{C}$ for $1 \mathrm{~min}, 10^{\circ} \mathrm{C} \mathrm{min}{ }^{-1}$ to $280{ }^{\circ} \mathrm{C}$, held for $4 \mathrm{~min}$. The injection volume was $1 \mu \mathrm{L}$ in the manual mode.

Helium was used as carrier gas at $1.5 \mathrm{~mL} \mathrm{~min}^{-1}$ and the make-up gas was nitrogen (UP grade) with total flow rate of $50 \mathrm{~mL} \mathrm{~min}^{-1}$.

\section{Sample preparation and fortification}

Grain samples were processed in a Tecnal TE650 grinder, as received in their raw, unwashed form, homogenized and kept in a freezer. A $5 \mathrm{~g}$ portion of the powdered grain sample was separated, placed into a mortar and $1 \mathrm{~g}$ of neutral alumina as solid phase was added. The material was fortified with $500 \mu \mathrm{L}$ of the mixed pesticide standard solution (concentration range of $0.5-3.0 \mu \mathrm{g} \mathrm{mL}^{-1}$ ). The mixture was then blended until homogeneous. The sample with solid phase and pesticides was then introduced into a cartridge ( $20 \mathrm{~mL}$ volume capacity). Glass wool was used to retain the entire sample. The analytes were eluted with $40 \mathrm{~mL}$ ethyl acetate by gravity flow and the eluate was then concentrated using a Fisatom 802D rotary vacuum evaporator $\left(40-45^{\circ} \mathrm{C}\right.$ water bath, reduced pressure). The final volume was $5.0 \mathrm{~mL}$. These extracts were kept in a freezer and then transported in an appropriate box to maintain the low temperature until analysis on the chromatograph. The real rice samples were obtained from Perímetro Irrigado Betume, Sergipe State, which was submitted to the proposed method, but without being fortified.

\section{Recovery studies}

Recoveries of the three pesticides in rice were determined. Individual standard solutions of each pesticide were prepared in ethyl acetate at $200 \mu \mathrm{g} \mathrm{mL}^{-1}$. A standard mixed solution was prepared by mixing suitable volumes of individual standard solutions and diluting with ethyl acetate. Three untreated samples were fortified with a known quantity of the mixed pesticide standard solution at three levels. The recovery results were determined in triplicate. Recoveries were calculated from a standard curve prepared by diluting pesticide solutions with ethyl acetate, in the 0.2 to $2.0 \mu \mathrm{g} \mathrm{mL}^{-1}$ range. This calibration was performed both before and after each sample set.

\section{Results and Discussion}

In this work, the amount of sample was defined by the capacity of the column and by the ratio of solid phase to sample. A set of experiments was done with spiked matrices with the standard mixture, varying sample and solid phase amounts, solid phase (neutral alumina and silica) and eluting solvent (ethyl acetate and hexane).

Analyte removal from a matrix depends on analyte solubility in the eluting solvent, analyte-matrix interactions, localization of analyte inside the matrix and the interactions matrix-solid phase-eluting solvent. Rice matrices have low water content and this eliminates problems with the homogenization step.

The final extracts when utilizing silica show more sample co-extractives than does neutral alumina. Although both results were satisfactory, alumina showed a good performance in the extraction of pesticides residues from rice by MSPD. Therefore, neutral alumina was chosen. A five-to-one ratio of neutral alumina to rice gave the best recoveries and precisions.

In general, it is observed that the smaller the size of the particle matrix the more rapid and complete is the extraction. Thus, the presence of solid phase permitted clean up at the same time as extraction from the dispersion on the matrix.

Studies with different solvents (acetone, ethyl acetate, acetonitrile) showed that the solvation power of the organic solvent is practically constant, therefore the solvent not is a limiting factor for the elution of the compounds due to their polarity range. A first elution with hexane for removal of components extracted from the samples and then elution with ethyl acetate was studied, however no variation in 
the results was observed. In this work, the eluting solvent chosen was ethyl acetate, due to its advantageous characteristics, described previously. ${ }^{11,19}$ The $40 \mathrm{~mL}$ elution volume of ethyl acetate assures the total recovery of the added pesticides from the highly polar solid phase and is a convenient volume with which to initiate the next step.

The MSPD method used in this study differs from traditional methods in that, in most of these, the sample is dispersed over a $\mathrm{C}_{18}$ solid phase. Silica and alumina, used to disperse the pesticides found in rice, removes polar compounds from the sample and gives extracts with a minimum of ECD-sensitive compounds to interfere with detection of the pesticides. Generally, an additional cleanup step is recommended when using an ECD as the detection system, but in this work the extracts were clean using only a single step (extraction and clean-up at the same time).

Linear regression analysis was obtained for the three pesticides. An analytical curve using the mixed standard pesticide solutions was constructed by plotting concentration versus peak area (Table 1). The determination coefficients $\left(\mathrm{r}^{2}\right)$ of analytical curves were above 0.992 , with linearity for each compound, which allows the quantitation of these compounds by the method of external standardization.

The results reported here are based on an unfortified and three fortified samples for each pesticide concentration

Table 1. Linear regression analysis for the selected pesticides with GC-ECD

\begin{tabular}{lcccc}
\hline Compound & $\begin{array}{c}\text { Range } \\
\left(\mu \mathrm{g} \mathrm{mL} \mathrm{m}^{-1}\right)\end{array}$ & & Equation $^{\mathrm{a}}$ & $\mathrm{r}^{2}$ \\
\hline Parathion-methyl & $0.4-2.0$ & $1.310^{5} \mathrm{x}+6.510^{4}$ & 0.998 \\
Malathion & $0.8-4.0$ & $4.510^{4} \mathrm{x}+4.310^{4}$ & 0.992 \\
$\beta$-endosulfan & $0.2-1.0$ & $3.910^{5} \mathrm{x}+5.410^{4}$ & 0.998 \\
\hline${ }^{\mathrm{a}} \mathrm{y}=\mathrm{ax}+\mathrm{b}$. & & & &
\end{tabular}

level. All experiments have recoveries of 56.2 to $120.7 \%$. The use of the $1.0 \mathrm{~g}$ solid phase was more efficient than with $0.5 \mathrm{~g}$, for both adsorvents.

Analyses of the fortified rice samples with the selected pesticides were performed at different levels $(0.5-10.0 \mathrm{mg}$ $\left.\mathrm{kg}^{-1}\right)$. Mean recoveries for parathion-methyl, at levels of $1.0,2.0$ and $5.0 \mathrm{mg} \mathrm{kg}^{-1}$, ranged from 86.0 to $116.0 \%$, with relative standard deviations between 3.5 and $10.8 \%$, for malathion, at levels of $2.0,4.0$ and $10.0 \mathrm{mg} \mathrm{kg}^{-1}$, ranged form 75.5 to $107.9 \%$, with relative standard deviations between 4.1 and $10.9 \%$, and for endosulfan, at levels of $0.5,1.0$ and $2.5 \mathrm{mg} \mathrm{kg}^{-1}$, ranged from 89.7 to $110.4 \%$, with relative standard deviations between 0.5 and $7.0 \%$. Endosulfan showed the greatest precision (Table 3).

Ling and Huang ${ }^{18}$ developed an effective multi-residue MSPD method for 6 pesticides in $5 \mathrm{~g}$ of vegetables with 8 $\mathrm{g}$ portions of Florisil added for homogenization. A Florisil co-column and hexane-acetone eluent was used. The recoveries were between 92 to $113 \%$.

Tests were carried out with the proposed method to evaluate the use of MSPD technique as a method of storing the extracted compounds. The pesticides were added to the mixture of rice-alumina and triturated, then extracted at different time intervals: one minute, seven hours and one day. After these times the column was eluted with ethyl acetate and the aliquots collected were analyzed. The recovery results (Table 2) were 86.8 to $118.3 \%$. These results showed that for the pesticides selected for study,

Table 2. Effect of the storage time for pesticides on a MSPD column

\begin{tabular}{lcrrr}
\hline \multirow{2}{*}{ Compound } & Added & \multicolumn{3}{c}{ Recovery (\%) } \\
& $\begin{array}{c}\text { Standard } \\
\left(\mu \mathrm{g} \mathrm{mL}^{-1}\right)\end{array}$ & $(1 \mathrm{~min})$ & $(7 \mathrm{~h})$ & $(24 \mathrm{~h})$ \\
\hline Parathion-methyl & 2.00 & 89.7 & 90.3 & 86.8 \\
Malathion & 4.00 & 115.8 & 118.3 & 92.0 \\
$\beta$-endosulfan & 1.00 & 116.9 & 88.4 & 95.5 \\
\hline
\end{tabular}

Table 3. Average recoveries, relative standard deviations and limits of detection and quantitation for the pesticides in rice with the MSPD method

\begin{tabular}{|c|c|c|c|c|c|}
\hline \multirow[t]{2}{*}{ Compound } & \multirow{2}{*}{$\begin{array}{l}\text { Fortification level } \\
\qquad\left(\mathrm{mg} \mathrm{kg}^{-1}\right)\end{array}$} & \multicolumn{2}{|c|}{ Rice } & \multirow[b]{2}{*}{ LD (pg) } & \multirow[b]{2}{*}{ LQ (pg) } \\
\hline & & Average Recovery ${ }^{\mathrm{a}}(\%)$ & $\operatorname{RSD}(\%)$ & & \\
\hline \multirow{3}{*}{ Parathion-methyl } & 5.0 & 116.0 & 5.4 & \multirow{3}{*}{25} & \multirow{3}{*}{90} \\
\hline & 2.0 & 86.0 & 3.5 & & \\
\hline & 1.0 & 104.4 & 10.8 & & \\
\hline \multirow{3}{*}{ Malathion } & 10.0 & 107.9 & 6.4 & \multirow{3}{*}{105} & \multirow{3}{*}{350} \\
\hline & 4.0 & 75.5 & 4.1 & & \\
\hline & 2.0 & 91.0 & 10.9 & & \\
\hline \multirow{3}{*}{$\beta$-endosulfan } & 2.5 & 104.4 & 0.5 & \multirow{3}{*}{20} & \multirow{3}{*}{65} \\
\hline & 1.0 & 89.7 & 3.9 & & \\
\hline & 0.5 & 110.4 & 7.0 & & \\
\hline
\end{tabular}

${ }^{\mathrm{a}} \mathrm{n}=3$ repetitions. 
the MSPD technique can be used to store samples for up to one day.

LQ (limit of quantitation), defined as a response ten times the average height of the blank baseline noise, was in the range of 65 to $350 \mathrm{pg}$. For LD (limit of detection), defined as a response three times the average height of the blank baseline noise, the results were founded in the range 20 to 105 pg (Table 3 ). ${ }^{20}$

A commercial rice sample obtained in Perímetro Irrigado Betume (Sergipe State irrigation region) was analyzed by the MSPD proposed method. None of the studied pesticides were detected.

In conclusion, the proposed multi-class MSPD method described here can be applied to the extraction of organophosphorus and organochlorine pesticides from rice. The best conditions were defined and neutral alumina was used as extracting solid the matrix. It is an advantageous method because it requires small sample sizes, a short time for analysis and demands only a small amount of solvent, compared to liquid-liquid extraction.

\section{Acknowledgments}

We acknowledge Prof. Jailson Bittencourt de Andrade (Laboratório de Pesquisas e Desenvolvimento em Química$L P Q$ ) at Universidade Federal da Bahia, Brasil, for the use of the gas chromatograph, José Ricardo L. Bispo for collecting the real samples, and $\mathrm{CNPq}$ and FAPESE for financial support.

\section{References}

1. http://www.cnpaf.embrapa.br, accessed in August 2002.

2. Dórea, H.S.; Barbirato, M.A.; Lanças, F.M.; Pesticidas 1997, 7, 109.
3. Nakamura, Y.; Tonogai, Y.; Tsumura, Y.; Ito, Y.; J. AOAC Int. 1993, 76, 1348

4. Pang, G.F.; Fan, C.L.; Chao, Y.Z.; J. AOAC Int. 1994, 77, 738.

5. Saikia, N.; Kulshrestha, G.; J. Chromatogr. A 1999, 864, 351.

6. Lanças, F.M.; Rissato, S.R.; J. Microcolumn Sep. 1998, 10, 473.

7. Beltran, J.; Lopes, F.J.; Hernandez, F.; J. Chromatogr. A 2000, 885, 389.

8. Santos, T.C.R.; Rocha, J.C.; Barceló, D.; J. Chromatogr. A 2000, 879, 3 .

9. Ahmed, F.E.; Trends Anal. Chem. 2001, 20, 649.

10. Barker, S.A.; Long, A. R.; Short, C.R.; J. Chromatogr. 1989, 475, 353.

11. Dórea, H.S.; Lanças, F.M.; J. Microcolumn Sep. 1999, 11, 367.

12. Viana, E.; Moltó, J.C.; Font, G.; J. Chromatogr. A 1996, 754, 437.

13. Torres, C.M.; Picó, Y.; Mañes, J.-J.; J. Chromatogr. A 1997, $778,127$.

14. Valenzuela, A.I.; Lorenzini, R.; Redondo, M.J.; Font, G.; $J$. Chromatogr. A 1999, 839,

15. Navarro, M.; Pico, Y.; Marin, R.; Manes, J.; J. Chromatogr. A 2002, 968, 201.

16. Barker, S.A.; J. Chromatogr. A 2000, 885, 115.

17. Barker, S.A.; J. Chromatogr. A 2000, 880, 63.

18. Ling, Y.C.; Huang, I.P.; J. Chromatogr. A 1995, 695, 75.

19. Dórea, H.S.; Tadeo, J.L.; Sanchez-Brunete, C.; Chromatographia 1996, 43, 380.

20. Long, G.L.; Winefordner, J.D.; Anal. Chem. 1983, 55, 712A.

Received: May 6, 2003

Published on the web: September 9, 2004 